\title{
A pedagogia experimental e a formação de professores (1950-1970): análise de duas experiências didáticas incomuns
}

\section{The experimental pedagogy and the formation of professors (1950- 1970): analysis of two uncommon teaching experiences}

\author{
${ }^{1}$ Pablo Silva Machado Bispo dos Santos psmbsantos@gmail.com \\ 2 Cecilia Neves Lima
}

\section{RESUMO}

O presente artigo tem como objetivo principal apresentar e analisar a experiência didática desenvolvida em duas instituições escolares brasileiras de destaque nos anos de 1950-1970: O Colégio Nova Friburgo e a Escola Guatemala. Para tanto, foram analisados documentos institucionais diversos e publicações sobre tais instituições. A perspectiva metodológica empregada foi a da História Cultural, que se caracteriza entre outras coisas, por relativizar o caráter de verdade absoluta contida em um documento, bem como em ampliar o conceito de fonte documental abarcando as dimensões culturais e políticas de sua produção. Ao fim do estudo, foi possível identificar dois elementos-chave: a) o papel da iniciativa privada na capacitação de professores em redes públicas de ensino; b) a emergência de um padrão de formação de professores baseado na noção de experiência educacional, o qual destinar-se-ia a multiplicar-se por todo o País por intermédio do Ministério da Educação e das redes de ensino.

Palavras-chave: Pedagogia Experimental, Formação de Professores, Experiência didática.

\section{ABSTRACT}

This paper aims to present and analyze the experience of teaching developed in two Brazilian prominent educational institutions in the years 1950-1970: Colégio Nova Friburgo and Escola Guatemala. To this end, several institutional documents and publications on such institutions were analyzed. The methodological approachemployed was that of Cultural History which is characterized, to qualify the character of absolute truth contained in a document, as well as extend the concept of documentary source covering the cultural and political dimensions of its production .At the end of the study, it was possible to identify two key elements : a) the role of private enterprise in the training of teachers in public schools , b) the emergence of a pattern of teacher training based on the notion of educational experience, which would be intended tomultiply throughout the country through the Ministry of Education and school systems.

Keywords: Experimental Pedagogy, Teachers training, Teaching Experience.

\footnotetext{
1 Professor Adjunto III, Departamento de Ciências Humanas - PCH, Líder do Núcleo de Pesquisas em Instâncias de Socialização e Ppolíticas Públicas - POLIS/UFF.

2 Professora Adjunta I, PCH - Departamento de Ciências Humana, UFF.
} 


\section{INTRODUÇÃO}

O presente trabalho visa a apresentar o histórico de duas perspectivas de formação de professores, com ênfase em formas distintas de didática experimental, baseadas no pragmatismo de John Dewey e na perspectiva pedagógica de Herbart ${ }^{3}$. Tais experiências foram desenvolvidas sob as denominações: método de projetos e método de unidades didáticas. Tais denominações compuseram os referenciais pedagógicos da Escola Guatemala e do Colégio Nova Friburgo (CNF), respectivamente.

Época de intenso desenvolvimento econômico, o período compreendido entre 1950 e 1970 configurou-se pelo surgimento de diversas iniciativas educacionais experimentais nas esferas pública (Escola Guatemala) e privada (CNF).

A metodologia de análise empregada foi a da História Cultural (CHARTIER,1993), cabendo indicar que tentamos a todo momento analisar as fontes tendo em vista o fato de que estas possuem, no momento de sua construção um caráter monumental no sentido de se deixarem impregnar neste momento pelas ideias, intenções e sentidos dos atores/autores oficiais (LE GOFF, 1985).

Dentre as fontes documentais que elegemos como objeto de análise, destacamos: a) depoimentos de ex-alunos, professores e funcionários do CNF; b) dois livros editados pela Fundação Getúlio Vargas sobre o CNF; c) a Revista Curriculum, editada pela Fundação Getúlio Vargas no âmbito do Colégio Nova Friburgo; d) texto relativo à XII Conferência Nacional de Educação de 1956, em que é apresentado a proposta pedagógica da Escola Guatemala, e) o documento intitulado “O Método de Projetos na Escola Experimental do INEP”, de 1956.

O presente estudo se apresenta dividido em quatro seções: a) Referencial Teórico-Metodológico; b) $O$ Centro de Estudos Pedagógicos do CNF: o experimentalismo pedagógico e a formação de professores na esfera privada: nesta seção é realizada uma análise da relação entre o Método de Unidades Didáticas e o Centro de Estudos Pedagógicos, órgão integrante do Colégio Nova Friburgo e que atuou entre os anos de 1960-1970 como núcleo formador de professores, formação esta que se dava através de estágios e convênios entre a Fundação Getúlio Vargas e as redes públicas de ensino do Estado do Rio de Janeiro; c) A Escola Guatemala e os Cursos de Aperfeiçoamento do Magistério: nesta seção se desenvolve uma análise da originalidade de várias das estratégias de formação de professores empreendidas no âmbito da Escola Guatemala, primeiro Centro Experimental do Instituto Nacional de Estudos Pedagógicos (INEP), com destaque aos cursos de formação continuada e de capacitação e treinamento de professores primários do País inteiro; d) Considerações finais, que analisam a contribuição dessas experiências no âmbito da formação de professores nas décadas de 50,60 e 70, tanto em nível local quanto em nível nacional.

\section{REFERENCIAL TEÓRICO-METODOLÓGICO}

No que tange ao referencial teórico, deve ser mencionado que na encruzilhada entre a História e a Educação surge a História da Educação, e na relação desta com a História Cultural se desenvolve a linha de estudos relativa à História das Instituições Escolares (LLOYD, 1995). Estas abordagens dão conta do cerne da perspec-

3 A respeito da Pedagogia de Herbart, Santos (2006) indica que setrata de uma perspectiva educacional vinculada a dois pressupostos básicos: a) a utilização das atividades didáticas e do espaço escolar como elementos de formação moral e construção das condutas éticas dos estudantes (particularmente no que se refere às crianças); b) o estabelecimento de um sistema de ensino com atividades pedagógicas direcionadas a uma aprendizagem por intermédio de etapas (denominadas "Passos da Instrução Formal") pedagógicas compostas por diversas modalidades de atividades cujas ênfases se assentavam sobre o desenvolvimento das habilidades de associação e memorização de conteúdos. 
tiva teórico-metodológica adotada, e representam a própria maneira segundo a qual posiciono o presente estudo em relação a seu enfoque e abrangência.

No tocante ao que se refere à relação destas abordagens com o presente estudo, cabe indicar que esta é uma pesquisa informada por uma perspectiva histórica, a qual alude ao estudo das relações particulares com o "eixo do tempo", de um objeto situado no espaço. Tornando mais específica a indicação das opções teóricas realizadas para a composição deste trabalho, deve ser mencionado ainda que o mesmo se apresenta calcado nos aportes teóricos da História Cultural (CHARTIER, 1993). A esse respeito, deve ser indicado que a História Cultural pode ser entendida simultaneamente como teoria e método, e ainda como uma forma de investigar as mudanças e permanências ocorridas em um dado objeto ao longo de um determinado tempo, do ponto de vista cultural, ou seja, trata-se de uma aplicação da história a elementos humanos, seja no que se refere aos elementos imateriais de sua relação com a cultura, como os símbolos, significados e discursos, seja no tocante aos elementos concretos, como espaços arquitetônicos, utensílios, documentos.

Partindo destas premissas, pode-se dizer que um outro conceito-chave deste trabalho é o de historiografia. Sobre tal conceito, Justino Magalhães indica que: A produção historiográfica, enquanto construção e representação discursiva da realidade, visa o conhecimento da relação, ou melhor, das relações, num contexto de multidimensionalidade (MAGALHÃES, 1988, p. 53).

Ao realizar o apontamento metodológico que dá conta da ênfase nos estudos comparados, porém partindo de uma perspectiva centrada na escola, Justino Magalhães fornece alguns elementos para que possa ser realizado um estudo histórico que, ao mesmo tempo, nem se permita ir em direção a "periodizações cronológicas por demais extensas e abordagens de objetos planetários” e nem tampouco ir em direção a objetos fragmentários o bastante para que se perca de vista o contexto histórico mais amplo que os condiciona. Partindo deste raciocínio, pode-se afirmar que o autor entende a historiografia como uma forma particular relacional de trabalhar (pelas vias do discurso e da representação) os objetos de estudo, que são construídos em função de suas ligações com o eixo matricial espaço-tempo. Com base no que foi exposto, duas categorias de entendimento se mostraram fundamentais para a construção de nosso objeto de análise. Abaixo apresentamos as referidas categorias.

\section{1 Memória}

Segundo BERGSON (1999), a memória é um componente da realidade, presente não só na dimensão "mental” ou "espiritual” do sujeito, mas que estaria inscrita na própria materialidade dos elementos da realidade concreta (o que inclui, sem dúvida alguma a dimensão biológica concernente ao corpo do pesquisador), sendo assim capaz de reter registros de eventos ocorridos, prontos para serem "lidos" (ou interpretados) pelos sujeitos que se defrontam com os registros de memória. Outros autores, assim como Bergson, vão propor acepções de memória que igualmente asituam para fora do sujeito. Exemplo disto se apresenta na proposta de Halbwachs(1990), autor que indica que a memória não é propriedade exclusivamente individual, mas sim um elemento de caráter igualmente coletivo. Segundo Dosse, esse autor divide a memória coletiva em algumas dimensões, podendo, por exemplo, estar presente na dimensão institucional da coletividade (expressa, principalmente, nos rituais e regras sociais do cotidiano). Este foi um autor que muito teria feito avançar os estudos históricos, notadamente no sentido de investigar de que maneira a memória individual se imiscui na memória coletiva, passível de ser alvo,assim como a memória coletiva,de estudos da história cultural, desde que respeitadas as cisões entre memória e história que teriam: "do lado da memória individual, o vivido, o múltiplo, o sagrado [o sensorial] e do lado da história o caráter crítico, conceitual, problemático [o racional]” (DOSSE, 2005, p. 280).

Sobre a memória coletiva, Dosse indica que Halbwachs a define da seguinte forma: a memória coletiva apresenta-se como um rio que alarga seu leito sobre uma linha contínua, enquanto a história recorta períodos e diferenças, as mudanças e descontinuidades(p. 281).Neste sentido, o conceito de memória coletiva institucionalizada reveste-se de vital importância para o presente trabalho, na medida em que muitas das fontes vêm 
a se configurar como registros de memória, portadores de elementos da história das instituições investigadas e que mediante o estudo sistemático destes registros é possívelpermitir a reconstrução de alguns dos caminhos já perdidos e/ou esquecidos de sua(s) história(s).

\section{2 Práticas e Representações}

Neste trabalho adotamos uma perspectiva teórica que entende as fontes documentais como elementos heurísticos de grande valor, mas cujo conteúdo não deve ser tomado como verdade absoluta sem uma prévia relativização do seu sentido, fundamentada por uma análise que busque compreender os significados subjacentes à materialidade da fonte documental (CHARTIER, 1993).

Tal perspectiva pressupõe a ideia de que o olhar do pesquisador deve voltar-se simultaneamente para as práticas e para as representações das práticas, elementos estes presentes nos registros de memória que se vão investigar (desde documentos até utensílios, elementos da arquitetura e grafismos), e que para que isto seja possível é necessário indagar as fontes, e "fazê-las falar" (LE GOFF,1985-a), ou seja, ter em mente a ideia de que as fontes de investigação não possuem uma verdade encerrada em si mesma, e que, para que seja possível compreender alguns dos múltiplos sentidos possíveis para sua existência, é necessário ter em mente a premissa de que o autor do documento muitas vezes o transforma em um "monumento" na medida em que pretende que este seja um repositório da memória que se pretendia guardar (LE GOFF, 1985-b). Seguindo esta linha de raciocínio, igualmente há que se indagar a respeito de quais práticas e quais representações poderiam ter afetado o objeto a que se destina um dado estudo, bem como as relações entre este objeto e o eixo matricial "espaço-tempo".

No estudo que desenvolvemos e apresentamos no presente trabalho esta diretriz se mostra muito relevante, na medida em que, ao confrontar-me com diversas fontes documentais, tenho então subsídios teóricos que permitem deslindar (ao menos em parte) a monumentalização de que teriam sido objeto os documentos a serem investigados. A seguir apresentamos o modo como tais categorias se combinaram no âmbito da análise dos dados deste trabalho.

\section{3 O processo de análise dos dados}

As categorias temáticas em que nos apoiamos, longe de comporem uma espécie de “camisa-de-força” teórica, atuaram de modo a auxiliar no processo de interpretação da realidade a que nos dispomos realizar. Quanto à análise dos dados, deve ser ressaltado que as fontes trazidas pelos documentos foram analisadas de modo a procurar captar os nexos de sentido existentes entre os mesmos, mediante o crivo de três operações: a)seriação e comparação de fontes (BRAUDEL, 2001; SANTOS, 2010); b) análise de conteúdo dos documentos a partir da segmentação do discurso (BRITTO, 2000; FRANCO, 2007); c) análise retórica global dos discursos produzidos pelos atores focalizados nos depoimentos e documentos (PERELMAN, 2001; REBOUL, 2007).

\section{O CENTRO DE ESTUDOS PEDAGÓGICOS DO CNF: O EXPERIMENTALISMO PEDA- GÓGICO E A FORMAÇÃO DE PROFESSORES NA ESFERA PRIVADA}

Em 1949, é criado o Colégio Nova Friburgo da Fundação Getúlio Vargas, sob a denominação de Ginásio Nova Friburgo (GNF). Na solenidade de inauguração, datada de 1950, em discurso de autoria do Professor 
Lourenço Filho ${ }^{4}$, este ilustre educador brasileiro assinala que: "É uma vocação da cidade de Nova Friburgo, a capacidade de desenvolver empreendimentos educacionais de alta significação e grande qualidade (...) a forma de escolha dos membros do seu corpo docente pode trazer a este estabelecimento desde o seu início, elementos de grande mérito (CARVALHO, 1988, p. 26)”.

Nesta passagem do seu discurso o Professor Lourenço Filho indica a importância da seleção de professores como forma de garantir o sucesso da empreitada desenvolvida pela FGV na criação do GNF. Mostra-se claro que esta preocupação com a seleção do corpo docente aponta para uma ideia de que o GNF poderia vir a se constituir em um núcleo de aplicação das metodologias didáticas desenvolvidas em cursos normais e nas universidades, atuando, nesse sentido, de maneira decisiva na formação de professores em nível de excelência conforme propõe o Professor Lourenço Filho, com vistas a tornar dessa maneira, concretos (pelo menos em parte) os objetivos propostos na implantação do GNF.

Após o seu primeiro ano de funcionamento, em 1951, o então intitulado Ginásio Nova Friburgo passa a se chamar Colégio Nova Friburgo, desta época datam as primeiras turmas do então curso primário. Entre 1951 e 1957, o CNF é dirigido por cinco professores. Em relação aos ocupantes do cargo de diretor, cabe indicar queem 1951, o CNF é dirigido por Theodomiro Rothier Duarte;de 1952 a 1953, é dirigido por Amaury Pereira Muniz; em 1954, Abelardo de Paula Gomes dirige o CNF; em 1955, Euclides Pereira de Mendonça.Como elemento de destaque do ponto de vista da proposta de formação de estar à frente da direção do CNF, em 1956 a direção é ocupada por Daniel Valle Ribeiro. Por sua vez, em 1957, Antônio de Souza Campos dirige o CNF. No que se refere aos critérios de escolha dos diretores, é conveniente ressaltar que até 1954estes eram nomeados pela FGV; entre 1954 e 1958 estes eram escolhidos mediante um processo de "rodízio anual" em que os diretores eram escolhidos pelos próprios docentes do CNF, e de 1959 até 1977 ocorre o retorno à prática da nomeação dos diretores por parte da FGV.

No que diz respeito ao trabalho desenvolvido em conjunto pelos professores do CNF, há que ser mencionada a criação do Centro de Estudos Pedagógicos (CEP), o qual teria sido:

(...) planejado em 1956 e criado em março de 1957 (...) o CEP realizou cursos de aperfeiçoamento, participou de encontros de professores, levou professores para outras cidades nas jornadas pedagógicas (...) recebeu educadores para estágios no Colégio, e programou seminários e séries de palestras e conferências para colegas de magistério pertencentes a outras instituições (CARVALHO, 1988; p. 155).

Assim, é correto afirmar que o CEP teria desempenhado um papel de enorme destaque no que se refere ao âmbito do CNF (e da própria FGV). Nas palavras de Irene Mello Carvalho: “O Centro de Estudos Pedagógicos, através de cursos, aperfeiçoou 5.547 professores no período de 1957-1977” (CARVALHO, 1988; p.155). Este órgão do CNF prestou ainda assessoria à Secretaria Estadual de Educação do Rio de Janeiro, bem como a diversas secretarias municipais de educação (como as de Nova Friburgoe Volta Redonda) no que se refere à elaboração de concursos e demais processos seletivos de professores para estas redes de ensino. A esse respeito, a autora afirma que:

(...) a FGV abriu as portas do Colégio para que diretores, técnicos de educação, professores e licenciandos de outras instituições que ali fossem estagiar ou realizar cursos de aperfeiçoamento. Julgava aconselhável, ainda, que os educadores do CNF difundissem suas experiências e os resultados de seus esforços em outros centros educacionais (CARVALHO, 1988; p. 153).

4 Deve ser destacado que Manoel BergströmLourenço Filho foi um educador muito influente nos rumos do ensino no Brasil, especialmente nos anos de 1930-1960. Deve-se a ele o papel de divulgador e responsável pela implantação dos testes psicométricos de maturidade de estudantes,denominados Testes ABC. Igualmente foi um autor importante para a Administração Escolar, sendo responsável por boa parte das estratégias de planificação educacional desenvolvidas pelo MEC entre 1950-1970 (em conjunto com Anísio Teixeira, muitas vezes).Quem desejar obter maiores informações relativas à vida e obra do Professor Manuel Bergström Lourenço Filho poderá fazê-lo ao consultar o verbete com seu nome no Dicionário de Educadores no Brasil (Fávero \& Britto, 2001). Sobre as publicações mais relevantes deste autor, deve ser consultada a sua coleção temática, mantida pelo Instituto Nacional de Estudos e Pesquisas Educacionais Anísio Teixeira (INEP). Tal coleção encontra-se disponível para consulta eletrônica no site: http://www.publicacoes.inep.gov.br/resultados.asp?cat=11\&subcat=31\# . Consultado em 28/03/2014. 
Eis aí uma importante estratégia de irradiação das metodologias didáticas experimentais do CEP, pois pela via da assessoria técnica às secretarias municipais e dos cursos para professores, as inovações pedagógicas se tornariam conhecidas em outros espaços, bem como poderiam vir a se incorporar ao currículo de outras instituições e redes de ensino, contribuindo desta maneira para difundir os aspectos pedagógicos da didática experimental desenvolvida no CNF. Tal perspectiva se apoiava fortemente nos passos da instrução formal de Herbart, e no ensino por unidades, criado em 1926por Henri Morrison (Cf. CARVALHO, 1969). Conforme demonstrado em outro trabalho (Cf. SANTOS; 2005), o Método de Unidades Didáticas consistiu principalmente em uma atualização dos passos da instrução formal de Herbart, adaptados à realidade do Colégio Nova Friburgo através do estudo destes passos realizado por Henri Morrison em 1926. Assim, é correto afirmar que o Método de Unidades Didáticas seria uma espécie de terceira versão da pedagogia herbartiana, funcionando no Brasil entre as décadas de 1950 e 1970 no âmbito do Colégio Nova Friburgo.

Após o ano de criação do CEP, o Professor Amaury Pereira Muniz (que foi o diretor que permaneceu mais tempo à frente do Colégio) retoma a Direção do CNF em 1958, permanecendo até 1965. Do ponto de vista de sua estrutura administrativa, o CNF sofreria ainda três alterações:em 1966 e até 1967 esteve sob a direção de José Jorge Abibe nos anos de 1968 e 1976, período em que Amaury Pereira Muniz está mais uma vez à frente da direção do CNF, até sua extinção no ano de 1977. Após serem apresentados os aspectos alusivos à administração do CNF, destaco alguns elementos relativos ao alunado do Colégio. A esse respeito, seria interessante mencionar que, durante os seus aproximadamente vinte e oito anos de existência, o Colégio Nova Friburgo teve um total de 8756 alunos matriculados, sendo destes 2.736 bolsistas. No ano de 1970 ocorre o maior índice de matrículas, num total de 441 alunos, dos quais 131 eram bolsistas. No que se refere aos critérios de seleção do alunado, Irene Mello Carvalho afirma que:

O dept ${ }^{0}$ de Ensino da Fundação Getúlio Vargas era responsável pela seleção dos alunos internos, no âmbito dos testes de nível mental e de escolaridade (provas de português e de matemática, fundamentalmente). (...) complementando a seleção intelectual com a investigação de traços da personalidade dos novos candidatos (...) Os alunos semi-internos, residentes em Nova Friburgo, eram selecionados pelo próprio Colégio em moldes similares (...) Para os candidatos a bolsas de estudo, os critérios de aprovação eram mais rigorosos, o que é perfeitamente compreensível (CARVALHO, 1988; p. 63).

Ao examinar o processo de seleção descrito por Irene Mello Carvalho, faz-se mister recordar o discurso do Dr. Luiz Simões Lopes, proferido na solenidade de inauguração do CNF, no qual afirma que o recém-inaugurado ginásio da FGV deveria se destinar à formação de uma elite, elite esta que, ao que tudo indica, seria recrutada tendo em conta os parâmetros de distinção econômica (no caso dos alunos não-bolsistas, devido ao alto custo das mensalidades), de "aptidão psicológica” e desempenho intelectual (assim como visto na citação relativa ao processo de seleção do alunado do CNF). ${ }^{3}$ Destacam-se aí o Prof. Amaury Pereira Muniz, Diretor do CNF e a Prof ${ }^{a}$ Maria Zely de Souza Muniz, coordenadora do CEP entre 1964 e 1972.

Eram chamados de alunos bolsistas os professores e profissionais de educação que faziam os cursos de aperfeiçoamento do magistério ministrados pelo Instituto Nacional de Estudos Pedagógicos (INEP) e sua divisão de pesquisa aplicada, o Centro Brasileiro de Pesquisa Educacionais (CBPE). Esses cursos em sua maioria continham uma parte mais teórica (por assim dizer) que era realizada nas dependências do CBPE e uma parte prática de observação que era desenvolvida no interior da Escola Guatemala.

Cabe ainda mencionar quevários professores vinculados ao CEP participaram da iniciativa de criação de uma revista intitulada Curriculum, destinada em grande parte a divulgar os trabalhos experimentais dos docentes do CNF. Este periódico é editado de 1962 a 1976 e constitui um exemplo das estratégias de divulgação do ideário do CNF, cuja materialização se encontraria concentrada em grande parte no Centro de Estudos Pedagógicos do Colégio. 


\section{A ESCOLA GUATEMALA E OS CURSOS DE APERFEIÇOAMENTO DO MAGISTÉRIO}

A experiência da Escola Guatemala, no tocante ao aperfeiçoamento do magistério nas décadas de 1950/1960,se configurou como polo estratégico no projeto de renovação educacional do INEP / CBPE no período. Isso se deve não só ao momento histórico que Brandão (1997) denomina como um momento de consenso (clima propício), marcado pela crença no desenvolvimento da área educacional em bases científicas, bem como conta às mudanças e complexidades da sociedade daépoca, mas como forma de se estruturar no Brasil uma rede de conhecimentos que pudessem dar conta das necessidades do momento.

O projeto do CBPE buscava criar um estatuto científico para a educação fundamentado no experimentalismo e possuía papéis importantes. Nesse contexto, a Divisão de Aperfeiçoamento do Magistério (DAM) era a responsável pelo desenvolvimento de projetos de aperfeiçoamento do magistério, não apenas de professores de escolas normais, mas de administradores, orientadores e especialistas em educação. Os projetos de aperfeiçoamento do magistério tinham basicamente três eixos de atuação:

a. cursos de aperfeiçoamento do magistério oferecidos a professores (sobretudo primários) e profissionais de educação;

b. política de publicações de livros e guias de ensino que auxiliassem os professores de todo o país em sua prática;

c. manutenção de escolas e classes experimentais que servissem de espaço privilegiado de produção e testagem de metodologias.

De acordo com Lima (2008), aliado aos três eixos também havia dedicação a estudos e pesquisas, com o desenvolvimento de inquéritos e levantamentos sobre temas educacionais específicos de modo a subsidiar as ações citadas $^{5}$. Assim a circulação dos conhecimentos produzidos pelo Centro e adquiridos pelos professores através da aquisição de livros e/ou da participação em um curso, proporcionava ao professorado brasileiro contato com as inovações pedagógicas e estudos científicos relativos às temáticas educacionais. As ações da Divisão giravam em torno da melhoria do professorado brasileiro com ações integradas que visavam promover a profissionalização do magistério, bem como sua valorização frente à sociedade moderna e industrial que se formava no período.

Através do convênio firmado entre a Secretaria de Educação e o INEP, a Escola Guatemala, escola regular da rede de ensino do Distrito Federal, passou a condição de escola experimental em 15 de maio de 1955.

Administrativamente,a escola era subordinada à Secretaria de Educação, com responsabilidade sobre as matrículas dos alunos, relação de pessoal, avaliações etc. A cessão da escola ao INEP ocorreu apenas no âmbito pedagógico, já que administrativamente mantinha-se sob a gestão da Secretaria de Educação.

A escola, além de seu trabalho educativo (escolar) regular, recebia alunos bolsistas de outros Estados que acompanhavam o trabalho pedagógico ali desenvolvido. A dinâmica dos cursos de aperfeiçoamento acontecia daseguinte forma: os bolsistas permaneciam na escola no período da manhã, acompanhando as turmas e as professoras e àtarde frequentavam os cursos do INEP/CBPE. No fim da tarde, retornavam àescola para as reuniões conjuntas com os especialistas do INEP e as professoras regentes. Os alunos bolsistas participavam intensamente do cotidiano da escola, sem que os professores regentes tivessem receio de "mostrar" seu trabalho, pois toda a atividade pedagógica era discutida, refletida e orientada pelas técnicas do INEP.

5 Os estudos e pesquisas citados tinham como principal objetivo subsidiar a DAM com dados da realidade que dessem conta da demanda específica que surgia ao longo da elaboração e execução de suas atividades. Esses estudos não possuíam caráter sistêmico, eram desenvolvidos apenas como forma de suprir as necessidades da Divisão e não tinham interferência nos estudos das demais Divisões. 
Esta atividade da escola estava diretamente relacionada à formação e aperfeiçoamento do magistério, pois cada aluno bolsista ali estagiando tinha a oportunidade de estar em contato direto com uma experiência educacional nova, experimental, que poderia servir de exemplo bemsucedido para a generalização em todo o país.

Em relação à dinâmica organizativa dos cursos, estes tinham em média duração de 1 ano e os alunos permaneciam na cidade todo o tempo do curso. De modo geral, os cursos iniciavam-se e findavam-se no mesmo ano, com o retorno dos alunos as suas cidades de origem. É interessante observar também que o INEP/CBPE, através de sua estrutura organizativa, proporcionava aos alunos bolsas-auxílio para a manutenção dos mesmos na cidade, ou seja, o tempo de permanência dos alunos-bolsistas era subsidiado.

Além disso, durante a estada dos alunos, o INEP/CBPE destinava uma verba especial para eventos culturais na cidade, com a presença dos professores regentes dos cursos acompanhando seus bolsistas. Podemos perceber que essa estratégia tinha como objetivo principal, além do entretenimento e do fortalecimento dos laços cooperativos e da troca de experiências entre os participantes dos cursos e os professores, que estes adquirissem a maior quantidade de capital cultural possível durante o tempo de permanência no Distrito Federal (DF).

Os locais de realização dos cursos eram variados. Ocupando o terceiro andar da sede do CBPE no DF, a DAM possuía uma ampla sala no mezanino do prédio especialmente para as aulas dos cursos. Nesse espaço ocorriam cursos diversos e também servia para a execução da parte teórica de alguns cursos que tinham sua parte prática e de observação na Escola Guatemala ou em outra instituição especializada.

De modo geral, os cursos tinham aulas de disciplinas relativas ao conteúdo pedagógico, de disciplinas relativas ao assunto específico do curso e, quando necessário, eram inseridas disciplinas extras ao programa do curso. As aulas de cada disciplina tinham em média uma hora de duração.

Esperava-se que os professores entrassemem contato com as inovações pedagógicas propostas pelo Centro através de cursos oferecidos, tendo acesso a novas metodologias de ensinopautadas nos princípios científicos das ciências sociais, de forma a contribuir para a melhoria da prática docente, ese tornariam multiplicadores dos novos métodos de ensino, já que a maioria dos cursos contava com a presença de alunos de outros estados e regiões do país.

Cada curso possuía apenas uma única turma por ano. Essa estratégia tinha como objetivo principal a manutenção da qualidade do curso oferecido, além de ser uma forma de produzir maior integração entre professores e alunos, na tentativa de estreitamento dos laços de amizade e identificação de objetivos pedagógicos.

Noteque tanto a convivência dos alunos com os professores regentes em atividades culturais quanto a convivência entre os mesmos na sala de aula propiciavam a formação de uma rede de conhecimentos, por esta ser formada por pessoas de diferentes regiões e com diferentes experiências de vida que, naquele momento, compartilhavam de um objetivo comum e que, ao mesmo tempo, seriam agentes multiplicadores da experiência adquirida nessa convivência.

De acordo com a professora Maria do Carmo Marques Pinheiro ${ }^{6}$, a seleção dos professores que ministravam os cursos ficava a cargo a professora Risoleta Ferreira Cardoso, a responsável pela coordenação dos cursos de aperfeiçoamento do magistério e subordinada à diretora da DAM, Lúcia Marques Pinheiro. A escolha se dava de forma subjetiva, visto que os professores eram convidados a participar do projeto por sua competência profissional e por sua afinidade com a filosofia educacional do Centro. Essa forma de escolha dos profissionais se 
constituía em vantagens para o trabalho na medida em que todos os profissionais ali envolvidos possuíam afinidades político-pedagógicas, o que favorecia o trabalho e permitia que os cursos tivessem uma unidade filosófica.

Além disso, o INEP/CBPE contava com uma linha de publicações que se constituíam em objetos formativos dos professores. Fazendo parte de uma coleção de livros que tiveram importância no cenário educacional brasileiro, tinham sua distribuição gratuita a professores de todo o país para que estes tivessem conhecimento da produção científica educacional brasileira e pudessem atuar como multiplicadores dessa nova visão educacional, contribuindo para a renovação do ensino primário à época. Dentre as diversas obras dessa linha editorial, podemos destacar algumas publicações resultantes da experiência da escola Guatemala, entre elas primeiramente o guia de ensino Ensinando Matemática à Criança, de 1963.Também podemos citar o guia Estudos Sociais na Escola Primária $-1^{\circ}$ ao $4^{\circ}$ ano,testados pelaEscola Guatemala juntamente com outras classes experimentais em Minas Gerais e na Bahia.

Além disso, é importante destacar a importância da Escola Guatemala como espaço de formação e experimentação pedagógica. Os alunos-bolsistas dos cursos que necessitavam de observação e/ou estágios permaneciam na escola no período da manhã, acompanhando as turmas e as professoras, e àtarde frequentavam as aulas (ditas mais teóricas) dos cursos na sede do CBPE. No fim da tarde, retornavam àescola para as reuniões conjuntas com os especialistas do INEP e as professoras regentes. Os alunos bolsistas participavam intensamente do cotidiano da escola, pois toda a atividade pedagógica era discutida, refletida, pesquisada e orientada pelas técnicas do INEP.

Podemos citar, como exemplo, alguns cursos que tiveram na Escola Guatemala espaço privilegiado de observação e prática pedagógica. São eles:

a. Seminário de Sociologia para Professores de Escolas Normais, em 1957;

b. Cursos de Preparação de Professores de Linguagem na Escola Primária, de Escolas Normais e Institutos de Educação, em 1958 e 1959;

c. Curso de Matemática na Escola Elementar, em 1958;

d. Estágios de Aperfeiçoamento de Professores Primários para Escolas de Demonstração, de 1956 a 1960;

e. Curso de Especialização em Recreação e Jogos, em 1960;

f. Estágio de Preparação de Professores para Excepcionais, em 1958;

g. Cursos de Especialização em Arte Infantil, em 1956, 1958 e 1959.

Face ao exposto,percebe-se que as múltiplas dimensões das ações pedagógicas do INEP/CBPE tinham ampla integração. O trabalho girava em torno da formação de uma nova postura pedagógica dos professores e do contato com as inovações educacionais produzidas pelo INEP/CBPE e pelos próprios professores bolsistas dos cursos.

Vale destacar que a preocupação com a melhoria da formação docente era estendida também aos professores regentes da Escola Guatemala. Os professores da escola também participavam de cursos de aperfeiçoamento em outros estados. O Relatório dos trabalhos realizados pela Coordenação de Cursos de INEP de 1956 a 1960nos apresenta alguns dos cursos que os professores da Escola Guatemala participaram: 
- Estágios de Aperfeiçoamento de Professores Primários para escolas de Demonstração:

- Em 1956, realizaram o Estágio, na Escola experimental do INEP do Rio, 15 professores de vários Estados nos quais já existiam ou se planejava a criação próxima de escolas com as finalidades referidas: Paraíba, Pernambuco, Sergipe, Bahia, Paraná, Rio Grande do Sul e Goiás. Dezesseis professores, do então Distrito Federal, em exercício na Escola, igualmente receberam orientação (p. 26).

- Estágios de Aperfeiçoamento de Professores Primários de Escolas de Demonstração.

- Em 1959, sob a direção da professora Carmen Teixeira, 25 professores (12 de Brasília, 11 da Escola Experimental do INEP do Rio e 2 de Pernambuco) realizaram estágio na Escola Experimental da Bahia, observando todos os trabalhos ai realizados (p. 29).

- Estágio de Preparação de Professores para Excepcionais.

- Em 1957, o INEP colaborou financeiramente com a Sociedade Pestalozzi do Brasil para a vinda da Professora Maria Irene da Costa, de Portugal, a qual ministrou, durante os três meses de sua estada no Brasil, cursos sobre psicologia de crianças desajustadas, das quais foram também seguidos por 5 professores da Escola Experimental do INEP.Ainda em 1958, o INEP colaborou financeiramente com a Associação de Pais e Amigos dos Excepcionais para a realização de um Curso sobre Educação de Excepcionais, ministrado pelo professor Kenneth Lovell, da Universidade de Leeds - Inglaterra. (...) Incluiu também estágios em classes de crianças retardadas, em Jardins de Infância e Escolas primárias comuns e na Escola Experimental do INEP no Rio (p. 40).

Além disso, os docentes da escola também participaram de cursos no exterior:

Na mesma Universidade [Indiana], nos Cursos de 1957-1958 aperfeiçoaram-se 20 professores, sendo: 9 professores do Rio Grande do Sul, 6 professores de São Paulo e 5 professores da Escola Experimental deste Instituto no Rio, em diversos campos do Ensino Elementar, a saber: Administração Escolar, Psicologia infantil, estudos Sociais, Aritmética, Ciências Naturais, Artes Industriais, Educação Especial, Recursos Áudio-Visuais em Educação e Trabalho de Classe (p. 49).

Para finalizar, destaco a importância da integração entre as Divisões em prol da melhoria da qualidade educacional brasileira. A formação continuada permitia ao professor entrar em contato com inovações pedagógicas e propiciava uma formação prática baseada nos pressupostos da ciência experimental e do pragmatismo, o que significa dizer que foi uma experiência pioneira de formação continuada de professores no país. Outro fator que deve ser levado em conta era o tempo que os alunos-bolsistas passavam no DF, cerca de 1 (um) ano, o que proporcionava ao professor uma formação completa, abarcando as diversas dimensões do trabalho docente e da administração pública. Segundo Lima (2008):

O planejamento racional das ações levava os alunos-bolsistas a um "mergulho" nos estudos e reflexões sobre a educação brasileira, à medida que estes encontravam-se em outra cidade e com o pensamento focado em seu aprimoramento teórico e prático. Ao retornarem, levavam em suas malas, além de todo o conhecimento acumulado durante esse tempo e as experiências compartilhadas, o entusiasmo e a vontade de mudar a realidade escolar de suas regiões de origem com novas formas de encarar os problemas (p.121-122).

É importante destacar também que nesse período não havia pós-graduação no Brasil e a partir dessa iniciativa, os professores de todo o país tiveram a oportunidade de entrar em contato com as inovações pedagógicas produzidas pelos Centros. Podemos dizer que a estrutura de pesquisa montada pelo CBPE nas áreas de ciências sociais e educação, juntamente com suas ações de intervenção pedagógica como os cursos de aperfeiçoamento do magistério, foram profícuas ações que antecederam a institucionalização da pós-graduação no país. 


\section{CONSIDERAÇÕES FINAIS}

Conforme procuramos demonstrar neste trabalho, tanto a Escola Guatemala quanto o Colégio Nova Friburgo tiveram um papel de destaque na Educação Brasileira durante os anos de 1950-1970. Sob o aspecto da formação de professores, poucos são os estudos que detalham a atuação destas instituições no período supracitado. Estamos conscientes de que este é um esforço inicial de reconstrução da história da educação neste período, e que muitos acréscimos e contribuições podem ainda surgir a partir do aprofundamento da investigação iniciada.

No tocante à Escola Guatemala, é correto afirmar que a experiência mantida pelo INEP/CBPE foi de extrema importância para o momento educacional que o Brasil vivia nas décadas de 1950/1960, pois atuava com dupla função: a) como estratégia de renovação do ensino, na medida em que cada professor que por ali passava, seja como estagiário, seja como professor regente, assumia opapel de multiplicador da experiência, pois os conhecimentos construídos e internalizados a partir do trabalho cotidiano na escola eram disseminados através do ato educativo de cada professor em sua região; b) como instrumento formativo do professor, pois muitos daqueles estagiários estavam em contato com conhecimentos educacionais inovadores e experimentais, ou seja, o que havia de mais novo resultante do trabalho científico dos técnicos do INEP/CBPE e de pesquisas realizadas na própria escola, levando-os a formação e aperfeiçoamento de seu trabalho docente fundado em bases científicas, e provavelmente estas inovações ainda não estavam disponíveis em suas regiões de origem.

Assim, a Escola Guatemala, enquanto centro experimental do INEP/CBPE, foi uma instituição que atuou como polo irradiador de um projeto de formação continuada de professores em escala nacional, através dos cursos oferecidos pelo INEP/CBPE a professores de todo o país, constituindo-se num lócus de formação de professores nos anos de 1950-1960.

Naquilo que tange ao CNF, foi possível perceber que sua atuação no que se refere à formação de professores se deu a partir da ação do seu órgão interno, denominado CEP, que foi, ao que tudo indica, elemento auxiliar na estruturação dos sistemas de ensino do Estado do Rio de Janeiro nos anos de 1960-1970. Deve ser destacado o fato de que a formação de professores ocorria a partir de convênios, nos quais eram ministrados cursos de capacitação e treinamento, que atingiam também outras categorias de profissionais da educação, como supervisores escolares, administradores educacionais e orientadores pedagógicos. No âmbito destes cursos, a perspectiva pedagógica herbartiana contida no método de unidades didáticas (carro-chefe das metodologias de ensino desenvolvidas no CNF) era o elemento normatizador das já mencionadas atividades de formação de professores.

Neste sentido, cabe destacar que, no âmbito da iniciativa privada, a Fundação Getúlio Vargas promoveu durante os anos de 1950-1970uma experiência didática que incluía também a formação de professores pautada em uma perspectiva educacional que é reputada como "tradicional" (Cf. SAVIANI, 1980), mas que, pelo modo como foi utilizada no que se refere às atividades de ensino e de formação de professores, pode ser qualificada como experimental, e de certo modo, como inovadora.

À guisa de conclusão, defendemos a ideia de que este não é um estudo que se pretende definitivo acerca deste tema, mas sim um estudo que,esperamos, seja frutífero no sentido de lançar novas luzes a partes da história (e da memória) das instituições escolares e da formação de professores no Brasil. 


\section{REFERÊNCIAS}

BERGSON, Henri. Matéria e Memória. São Paulo: Martins Fontes, 1999. 284 p.

BRANDÃO, Zaia. “A Identidade do Campo Educacional: anotações com base no Ciência e Arte de Educar de Anísio Teixeira”. IN: MENDONÇA, A.W; BRANDÃO, Z.(orgs.) Uma Tradição Esquecida: Por que não lemos Anísio Teixeira? Rio de Janeiro: RAVIL, 1997. (Coleção escola de Professores). 238 p.

BRAUDEL, Fernand. Escritos sobre a História. Perspectiva: São Paulo, 1998. 306 p.

BRITTO, Jader de Medeiros. Diretrizes para análise de descritores. Rio de Janeiro: UFRJ, 2000 (mimeo). 46 p.

CAMBI, Franco. História da Pedagogia. São Paulo: UNESP, 1999. 983 p.

CARVALHO, Irene Mello. O Ensino por Unidades Didáticas: a experiência do Colégio Nova Friburgo. Rio de Janeiro: FGV, 1969. 202 p.

O Colégio Nova Friburgo da Fundação Getúlio Vargas: histórico de suas realizações. Rio de Janeiro: FGV, 1988. 266 p.

CHARTIER, Roger. A História Cultural: entre práticas e representações. Rio de Janeiro: Bertrand Brasil, 1993. $323 \mathrm{p}$.

ELIAS, Norbert. A Sociedade dos Indivíduos. Rio de Janeiro: Jorge Zahar, 1994. 188p.

FÁVERO, Maria de Lourdes de Albuquerque, BRITTO, Jader de Medeiros. Dicionário de Educadores no Brasil: da Colônia aos Dias Atuais. Rio de Janeiro: UFRJ, 2001. 2a Ed. Revista e Ampliada. 1012p.

FRANCO, Maria Laura Pugliesi Barbosa. Análise de Conteúdo. Brasília: Líber Livro Editora, 2005. 207 p.

HALBWACHS, Maurice. A Memória Coletiva. São Paulo: Editora Revista dos Tribunais, 1990. 223 p.

LE GOFF, Jacques. Documento/Monumento. In: Enciclopédia Einaudi, v.1, Memória-História. Porto: Inova/ Artes Gráficas, Imprensa Nacional - Casa da Moeda, 1985 (p. 158-178).

LIMA, Cecilia Neves. Ciência e Arte de Educar: a experiência da Escola Guatemala. 2004. 78f. Monografia (Licenciatura em Pedagogia) - Faculdade de Educação, Universidade Federal do Estado do Rio de Janeiro, Rio de Janeiro, 2004.

Formação de Professores no Distrito Federal: os cursos da Divisão de Aperfeiçoamento do Magistério (DAM/CBPE/INEP) nos anos de 1955 a 1964. 2008. 146f. Dissertação (Mestrado em Educação) Faculdade de Educação, Universidade Federal do Estado do Rio de Janeiro, Rio de Janeiro, 2008.

LLOYD, Christopher. As Estruturas da História. Rio de Janeiro: Jorge Zahar, 1997. 391 p.

MAGALHÃES, Jorge Um apontamento metodológico sobre a história das instituições educativas. In: CATANI, Denice Barbara. \& SOUZA, Carla Pereira (orgs.). Práticas educativas, Culturas escolares, Profissão docente. São Paulo, Escrituras: 1998. 218 p.

PASSOS, Cleo de Oliveira. Escola Guatemala: Uma Conversão do Olhar para a Construção do Currículo de uma Escola Experimental.1996. 198f. Tese (Doutorado em Educação) - Faculdade de Educação, Universidade Federal do Rio de Janeiro, Rio de Janeiro, 1996. 
PERELMAN, Chain, OLBRECHTS-TYTECA, Lucie. Tratado da Argumentação: a Nova Retórica. São Paulo: Martins Fontes, 2001. 546 p.

REBOUL, Oliver. Introdução à Retórica. São Paulo: Martins Fontes, 2007. 284 p.

SANTOS, Pablo Silva Machado Bispo dos. O Colégio Nova Friburgo da Fundação Getúlio Vargas: mergulhando em sua memória institucional. 2005. 132f. Dissertação (Mestrado em Educação) - Departamento de Educação, Pontifícia Universidade Católica do Rio de Janeiro, Rio de Janeiro, 2005.

O Ensino por Unidades Didaticas e a retomada da Pedagogia Herbartiana no Colégio Nova Friburgo.

Revista Educação Online, v.2, n.2, p. 110-121. Rio de Janeiro: PUC-Rio, 2006.

O Público, o privado e o ensino fluminense: o caso do Centro Educacional de Niterói (1960-1970). 2010. 312f. Tese (Doutorado em Educação) - Departamento de Educação, Pontifícia Universidade Católica do Rio de Janeiro, Rio de Janeiro, 2005.

SAVIANI, D. A Filosofia da Educação e o problema da inovação educacional no Brasil. In: GARCIA, Walter (org.). Inovação Educacional no Brasil: problemas e perspectivas. São Paulo: Cortez, 1980. 251 p.

Documentos - Arquivo Anísio Teixeira (CPDOC/FGV):

Escola Guatemala. AT 52.06.04, Fot. 0411-0434.

Panorama de Aperfeiçoamento de Pessoal Realizado pelo INEP, s/d.AT 52.06.04. F0478-0495.

Relatório dos trabalhos realizados pela Coordenação de Cursos do INEP de 1956 a 1960. AT 52.06.04. Fot. 0496-0521. 